\title{
EFEITO ALELOPÁTICO DE FRUTOS DE UMBU (Phytolacca dioica L.) SOBRE A GERMINAÇÃO E CRESCIMENTO INICIAL DE ALFACE E PICÃO-PRETO
}

\author{
Allelopathic effects of fruits of Phytolacca dioica $\mathrm{L}$. on the \\ germination and early growth of lettuce and beggartick
}

\author{
Junior Borella ${ }^{1}$, Lindamir Hernandez Pastorini ${ }^{2}$
}

\begin{abstract}
RESUMO
As plantas produzem substâncias por meio do metabolismo secundário. Quando liberadas no meio ambiente são capazes de interferir na germinação e no desenvolvimento de outras plantas. Objetivou-se, nesta pesquisa investigar os efeitos alelopáticos de umbu (Phytolacca dioica L.) sobre a germinação e o crescimento inicial de alface e picão-preto, em laboratório, utilizando-se extratos aquosos de frutos de umbu nas concentrações $0,1,2,4$ e $8 \%$; foi realizada análise fitoquímica dos frutos e testes de pH e potencial osmótico dos extratos de frutos. Analisaram-se, para a germinação os parâmetros: porcentagem de germinação (PG), velocidade de germinação (VG) e índice de velocidade de germinação (IVG); para o crescimento inicial analisaram-se os parâmetros: comprimento (radicular e da parte aérea) e biomassa (fresca e seca) das plântulas de alface e picão-preto. Os dados foram submetidos ao teste de Tukey, a $1 \%$ de probabilidade. Os parâmetros PG, VG e IVG foram alterados significativamente, proporcionais ao aumento da concentração dos extratos de frutos do umbu. O comprimento (radicular e da parte aérea) e a biomassa (fresca e seca) das plântulas de alface e picão-preto foram reduzidos significativamente com o aumento da concentração dos extratos aquosos de frutos de umbu. $\mathrm{O}$ pH e potencial osmótico dos extratos mantiveram-se dentro de padrões adequados e a análise fitoquímica revelou a presença de flavonoides. Pelos resultados os frutos de umbu apresentaram-se com efeito alelopático sobre a alface e o picão-preto.
\end{abstract}

Termos para indexação: Alelopatia, inibição, extratos aquosos.

\begin{abstract}
Plants produce substances through secondary metabolism. When these chemicals are released into the environment they can interfere in the germination and development of other plants. The objective of this research was to investigate the effects of allelopathic Phytolacca dioica L. on the germination and early growth of lettuce and beggartick, under laboratory conditions, using aqueous extracts of fruits of Phytolacca dioica at concentrations of $0,1,2,4$ and $8 \%$. Phytochemical analysis of the fruit was performed; and $\mathrm{pH}$ and osmotic potential of extracts of fruit were tested. We analyzed the following germination parameters: percentage of germination (PG), speed of germination (VG) and speed of germination index (IVG), for the initial growth parameters examined are: length (root and shoot) and biomass (fresh and dry) of seedlings of lettuce and beggartick. The data were submitted to Tukey's test at $1 \%$ of probability. Parameters PG, VG and IVG were significantly affected, with increase in concentration of the extracts of fruits of Phytolacca dioica. The length (root and shoot) and biomass (fresh and dry) of seedlings of lettuce and beggartick were reduced significantly with increasing concentration of the aqueous extracts of fruits of Phytolacca dioica. The $\mathrm{pH}$ and osmotic potential of the extracts were maintained within appropriate standards and phytochemical analysis revealed the presence of flavonoids. The results showed that the fruits of Phytolacca dioica presented allelopathic effect on the lettuce and beggartick.
\end{abstract}

Index terms: Allelopathy, inhibition, aqueous extracts.

(Recebido em 12 de janeiro de 2009 e aprovado em 24 de junho de 2009)

\section{INTRODUÇÃO}

O termo alelopatia, cunhado por Molisch em 1937, é empregado para caracterizar interações bioquímicas (maléficas ou benéficas) entre todos os tipos de plantas, inclusive microorganismos, por meio de substâncias químicas produzidas via metabolismo secundário e liberadas no meio ambiente. Entre as substâncias com atividades alelopáticas destacam-se taninos, glicosídeos cianogênicos, alcaloides, sesquiterpenos, flavonoides, ácidos fenólicos e outros (Rice, 1984).
As plantas têm capacidade de produzir aleloquímicos em todos os seus órgãos, no entanto sua concentração depende de diversos fatores, como solo, temperatura e pluviosidade, e essa produção tem fundamental importância no que diz respeito à autodefesa (Macías et al., 2007).

Os metabólitos podem ser liberados naturalmente pelas plantas que os produzem, podendo prejudicar ou favorecer as plantas direta ou indiretamente (Ferreira \& Aquila, 2000). Quando os metabólitos agem negativamente,

${ }^{1}$ Universidade Regional Integrada do Alto Uruguai e das Missões/URI - Cx. P. 709 - 98400-000 - Frederico Westphalen, RS - borellaj@gmail.com

${ }^{2}$ Universidade Regional Integrada do Alto Uruguai e das Missões/URI - Frederico Westphalen, RS 
a germinação e o crescimento são as etapas mais afetadas (Rice, 1984; Chon \& Kim, 2004).

O período de liberação e a quantidade de aleloquímicos liberados no meio ambiente determinam o impacto dos efeitos (Rodrigues et al., 1999). Efeitos alelopáticos podem afetar a diversidade de espécies, dominância, sucessão e clímax em agroecossistemas (Chou, 1999).

Esforços vêm sendo envidados nos últimos anos, especialmente com espécies arbóreas, a fim de verificar propriedades alelopáticas em espécies com potencial para compor sistemas agroflorestais e silvipastoris (Ferreira et al., 1992; Zhang, 1993).

O estudo de ações alelopáticas pode ser útil na busca por fitotoxinas naturais e de derivados sintéticos a serem empregados como herbicidas naturais, pois podem ser mais específicos em sua ação e menos prejudiciais ao meio ambiente (Smith \& Martin, 1994; Macías et al., 1998; Chou, 1999), minimizando o impacto ambiental, não comprometendo a qualidade dos recursos, a vida silvestre e a qualidade dos alimentos utilizados na dieta humana.

O umbu é uma espécie nativa de ocorrência desde o Rio de Janeiro, Minas Gerais e Mato Grosso do Sul até o Sul do Rio Grande do Sul na mata pluvial Atlântica e na floresta latifoliada semidecídua das bacias do Paraná e Uruguai, até altitudes de $850 \mathrm{~m}$. É uma planta pioneira e de rápido crescimento, utilizada em plantios mistos, em áreas degradadas e de preservação permanente e muito recomendada para o paisagismo. Considerada plantapadrão de boa terra, produz quantidade considerável de sementes viáveis todos os anos (Lorenzi, 2000).

Visto que o conhecimento de ações alelopáticas ainda é pouco conhecido, especialmente de espécies arbóreas e nativas, e não tendo sido encontrado relatos da ação ou competição do umbu sobre outras plantas, objetivou-se pesquisar os efeitos alelopáticos por meio de extratos aquosos de frutos de umbu sobre a germinação e o crescimento inicial de alface e picão-preto, em laboratório.

\section{MATERIAL E MÉTODOS}

O experimento de germinação e crescimento inicial foi conduzido no Laboratório de Fisiologia Vegetal da Universidade Regional Integrada do Alto Uruguai e das Missões - Campus de Frederico Westphalen - RS, de novembro de 2007 a junho de 2008. Para o preparo de extratos aquosos foram utilizados frutos frescos de Phytolacca dioica L., coletados em formações vegetais da região do Médio Alto Uruguai do estado do Rio Grande do Sul e imediatamente encaminhados ao laboratório, no qual se obtiveram os extratos.

Para o procedimento, os frutos frescos de umbu foram triturados em liquidificador industrial na proporção de
$8 \mathrm{~g}$ para $100 \mathrm{~mL}$ de água destilada (massa/volume), por $5 \mathrm{~min}$ em temperatura ambiente (extrato bruto). O extrato permaneceu em repouso por $24 \mathrm{~h}$ no escuro e sob refrigeração $\left( \pm 10^{\circ} \mathrm{C}\right)$, em seguida foi filtrado em gaze, seguindo-se centrifugação a $3000 \mathrm{rpm}$ por $10 \mathrm{~min}$. O sobrenadante foi utilizado como extrato de maior concentração (8\%). Repetiram-se os procedimentos e diluíram-se as alíquotas em água destilada para a obtenção de extratos nas concentrações 4,2 e $1 \%(\mathrm{~m} / \mathrm{v})$. Para comparar os efeitos das concentrações, utilizou-se como tratamento apenas água destilada (controle).

Para a realização do bioensaio de germinação e crescimento inicial foram utilizadas sementes de alface (Lactuca sativa L. cv. Grand rapidis) obtidas em comércio local e sementes de picão-preto (Bidens pilosa L.) obtidas a campo. As sementes de picão-preto foram previamente desinfestadas com hipoclorito de sódio a $2 \%$ por $30 \mathrm{~min}$, seguido de 5 enxágues com água destilada.

O experimento foi realizado em placas de Petri de $9 \mathrm{~cm}$ de diâmetro, contendo duas folhas de papel Germitest, devidamente esterilizadas, umedecidas com $5 \mathrm{~mL}$ de extratos aquosos de frutos de umbu, com suas respectivas concentrações. Todos os tratamentos, discriminados pelo tipo de extrato, foram constituídos por 4 repetições de 25 sementes (de alface ou picão-preto), distribuídas inteiramente ao acaso em câmara de germinação tipo BOD, a $25^{\circ} \mathrm{C}$, sob iluminação constante.

$\mathrm{O}$ registro do número de sementes germinadas foi realizado em intervalos de $24 \mathrm{~h}$ durante sete dias, considerando-se como critério de germinação a curvatura geotrópica da raiz (Ferreira \& Aquila, 2000). Para a análise da germinação foram considerados os parâmetros: porcentagem de germinação (PG), velocidade de germinação (VG) e índice de velocidade de germinação (IVG), calculados de acordo com Vieira \& Carvalho (1994).

Para análise do crescimento inicial consideraramse os parâmetros: comprimento (radicular e da parte aérea) e biomassa (fresca e seca). O comprimento radicular e da parte aérea foi obtido de 10 plântulas, totalizando 40 plântulas por tratamento, decorridos 7 dias da instalação do experimento, utilizando-se papel milimetrado. Posteriormente, obteve-se a biomassa fresca das amostras, por meio de pesagem em balança analítica, em seguida as plântulas foram acondicionadas em sacos de papel e colocadas em estufa de secagem por 7 dias a $40^{\circ} \mathrm{C}$, obtendo-se a biomassa seca.

Os extratos de frutos de umbu foram avaliados individualmente quanto ao $\mathrm{pH}$, aferindo-se com $\mathrm{pHmetro}$ (Tecnal), e potencial osmótico, estimado pelo método de Chardakov (Salisbury \& Ross, 1992). Também foram realizadas 
análises fitoquímicas dos frutos de umbu, via detecção de compostos de metabolismo secundário por meio de reações específicas, cuja presença ou ausência do aleloquímico foi identificada pela formação de precipitado ou aparecimento de coloração específica nas reações: taninos (métodos: reação com cloreto férrico, reação com acetato neutro de chumbo, reação com solução de acetato de cobre e reação com acetato de chumbo e ácido acético glacial); saponinas (métodos: reação de Rossol, reação de Mitchell, reação de Rosenthalen, reação com reativo sulfo-vanílico e reação de Liebermann); flavonoides (métodos: reação de Shinoda, reação com cloreto de alumínio, reação com cloreto férrico e reação com hidróxido de sódio); e alcaloides (métodos: reagente de Sheibler, reagente de Bourchardat, reagente de Bertrand, reagente de Mayer e reagente de Dragendorff), de acordo com métodos propostos por Costa (2001) e Falkenberg et al. (2002).

Os dados obtidos foram submetidos à ANOVA, comparados pelo teste de Tukey, a $1 \%$ de probabilidade, usando o programa Estat - Sistema de análises estatísticas (v.2,0) Unesp - Jaboticabal.

\section{RESULTADOS E DISCUSSÃO}

Analisando os efeitos ocasionados pelos extratos de frutos de umbu, observa-se interação significativa para porcentagem de germinação, velocidade de germinação e índice de velocidade de germinação e esses efeitos são mais significativos na germinação de sementes de picão-preto do que na germinação de sementes de alface (Tabela 1).

Reduções na PG de alface são observadas a partir do tratamento $4 \%$, e de picão-preto a partir do tratamento $2 \%$, submetidos a extratos aquosos de frutos de umbu (Tabela 1), quando comparados a seus respectivos controles. Observa-se inibição total da germinação de sementes de picão-preto, no tratamento submetido ao extrato aquoso de frutos de umbu na concentração $8 \%$. Embora a porcentagem de germinação das sementes de alface tenha sido reduzida, a velocidade de germinação não foi afetada, já a VG de picão-preto foi significativamente afetada a partir do tratamento $2 \%$. O índice de velocidade de germinação foi reduzido a partir do tratamento $4 \%$, para sementes de alface e a partir do tratamento $2 \%$, para sementes de picão-preto.

Para França et al. (2008), extratos orgânicos de nim (Azadirachta indica) provocaram a redução significativa da porcentagem de germinação de sementes de alface e picãopreto. Os efeitos observados respondem a uma relação dose dependente de acordo com o aumento da concentração dos extratos. No entanto Andrade et al. (2009), verificaram que extratos aquosos de folhas secas de tiririca não reduziram o percentual de germinação de sementes de alface, independente das concentrações utilizadas.

Segundo Medeiros \& Lucchesi (1993), extratos de ervilhaca (Vicia sativa L.) exerceram forte influência na germinação de sementes de alface, e em concentrações mais elevadas provocaram inibição total da germinação. Assim como Hoffmann et al. (2007) observaram redução na germinação de sementes de picão-preto devido à ação fitotóxica de oxalatos de cálcio associados com saponinas presentes no látex de extratos de comigo-ninguém-pode e espirradeira.

Diferenças significativas na velocidade de germinação de sementes de alface foram constatadas por Periotto et al. (2004) à medida que se aumentavam as concentrações de extratos de Andira humilis Mart. ex Benth., dos quais se atribui à presença de taninos nas folhas como sendo os responsáveis pelos efeitos inibitórios. Teixeira et al. (2004) constataram que determinados extratos de plantas de cobertura são responsáveis por atraso na velocidade de germinação de sementes de picãopreto e o atraso acentua-se com o aumento da concentração dos extratos. Extratos aquosos de espirradeira e comigoninguém-pode reduziram o índice de velocidade de germinação de sementes de alface e picão-preto com o aumento da concentração dos extratos (Hoffmann et al., 2007).

Tabela 1 - Valores médios da porcentagem de germinação (PG), velocidade de germinação (VG) e índice de velocidade de germinação (IVG) de sementes de alface e picão-preto submetidas aos extratos aquosos de frutos de umbu. URI, Frederico Westphalen, RS, 2008.

\begin{tabular}{ccccccc}
\hline \multirow{2}{*}{ Tratamento } & \multicolumn{4}{c}{ alface } & \multicolumn{2}{c}{ picão-preto } \\
\cline { 2 - 6 } & PG(\%) & VG(dias) & IVG(dias) & PG(\%) & VG(dias) & IVG(dias) \\
\hline controle & $99 \mathrm{a}^{*}$ & $1,202 \mathrm{~ns}$ & $22,417 \mathrm{a}$ & $86 \mathrm{a}$ & $3,620 \mathrm{~b}$ & $6,558 \mathrm{a}$ \\
$1 \%$ & $96 \mathrm{a}$ & $1,312 \mathrm{~ns}$ & $21,208 \mathrm{a}$ & $77 \mathrm{ab}$ & $3,619 \mathrm{~b}$ & $5,995 \mathrm{a}$ \\
$2 \%$ & $90 \mathrm{a}$ & $1,252 \mathrm{~ns}$ & $20,292 \mathrm{a}$ & $65 \mathrm{~b}$ & $5,043 \mathrm{a}$ & $3,420 \mathrm{~b}$ \\
$4 \%$ & $66 \mathrm{~b}$ & $1,427 \mathrm{~ns}$ & $13,333 \mathrm{~b}$ & $45 \mathrm{c}$ & $5,339 \mathrm{a}$ & $2,195 \mathrm{~b}$ \\
$8 \%$ & $26 \mathrm{c}$ & $1,729 \mathrm{~ns}$ & $4,5410 \mathrm{~b}$ & $0 \mathrm{~d}$ & $0,0 \mathrm{c}$ & $0,0 \mathrm{c}$ \\
\hline
\end{tabular}

* Médias seguidas pelas mesmas letras na coluna não diferem entre si pelo teste de Tukey, a 1\% de probabilidade. ns: não significativo. 
Quando foi analisado o crescimento inicial de plântulas de alface e picão-preto (Tabela 2), observaramse reduções significativas no comprimento (radicular e da parte aérea) e biomassa (fresca e seca). O comprimento radicular das plântulas de alface e picão-preto foi afetado quando submetidas a extratos aquosos de frutos de umbu em relação aos seus respectivos controles, à medida que se aumentou a concentração do extrato. $O$ comprimento da parte aérea da alface foi afetado, a partir do tratamento $4 \%$, e do picão-preto, a partir do tratamento $1 \%$.

Segundo Hoffmann et al. (2007), plântulas de picãopreto tiveram o comprimento radicular e da parte aérea reduzidos significativamente, à medida que se aumentaram as concentrações de extratos aquosos de espirradeira. Maraschin-Silva \& Aquila (2006) constataram que as plântulas de alface tiveram reduções acentuadas no comprimento radicular, quando submetidas a extratos de Erythroxylum argentinum O.E. Schulz e Ocotea puberula (Rich.) Nees, analisando o comprimento do hipocótilo extratos de Erythroxylum argentium e Luehea divaricata Mart. provocaram aumentos no comprimento em relação ao tratamento controle, já Ocotea puberula provocou redução.

Os extratos de umbu promoveram anormalidades no sistema radicular como raízes primárias atrofiadas e defeituosas e, em alguns casos, ausentes, bem como a ausência de raízes secundárias. Na Tabela 2, também pode se observar que o aumento da concentração dos extratos provocou o aparecimento de raízes curtas e desproporcionais às demais estruturas da planta (parte aérea). Esses sintomas também foram evidenciados por Gatti et al. (2004), Periotto et al. (2004) e MaraschinSilva \& Aquila (2006), ao testar efeito alelopático de extratos de determinadas plantas sobre o comprimento radicular e da parte aérea de alface. As disparidades observadas entre as estruturas (radiculares e da parte aérea) das plântulas, segundo Chung et al. (2001) devese ao fato de haver maior contato entre as raízes e o extrato (aleloquímicos) do que as demais estruturas das plântulas.

As biomassas fresca e seca (Tabela 3) também foram afetadas em ambas as plântulas (alface e picão-preto). A biomassa fresca de plântulas de alface foi reduzida a partir do tratamento $4 \%$ e do picão-preto apenas no tratamento $8 \%$, quando submetidos a extratos aquosos de frutos de umbu, em relação aos seus respectivos controles. A biomassa seca das plântulas foi afetada pelos extratos aquosos de frutos de umbu, em ambas as plântulas testadas, a partir do tratamento $4 \%$.

Medeiros \& Lucchesi (1993) não constataram alterações significativas na biomassa seca de plântulas de alface, quando submetidas a extratos de ervilhaca. Hoffmann et al. (2007) observaram redução das biomassas frescas e secas das plântulas de alface e picão-preto submetidas a extratos de espirradeira e comigo-ninguémpode e a redução é proporcional ao aumento da concentração dos extratos.

Quanto às características físico-químicas apresentadas pelos extratos de frutos de umbu, observa-se variação de $\mathrm{pH}$ em relação ao controle, no entanto permaneceram dentro de padrões aceitáveis para a germinação e crescimento de plântulas em testes alelopáticos. Os extratos apresentaram variação de $\mathrm{pH}$ entre 4,68 a 4,83. Quanto ao potencial osmótico, os valores apresentaram variação entre -0,0170 a -0,1390 MPa (Tabela 4).

Dados na literatura indicam que tanto a germinação como o crescimento de plântulas são afetados quando o pH é extremamente alcalino ou extremamente ácido com efeitos deletérios observados em condições de $\mathrm{pH}$ abaixo de 4 e superior a 10 (Eberlein, 1987), para Mayeux \& Scifres (1978), efeitos do pH sobre testes alelopáticos são ocasionados por $\mathrm{pH}$ abaixo de 3 e acima de 11 .

Tabela 2 - Valores médios do comprimento radicular e da parte aérea de plântulas de alface e picão-preto, submetidas aos extratos aquosos de frutos de umbu. URI, Frederico Westphalen, RS, 2008.

\begin{tabular}{ccccc}
\hline \multirow{2}{*}{ Tratamento } & \multicolumn{2}{c}{ alface } & \multicolumn{2}{c}{ picão-preto } \\
\cline { 2 - 5 } & $\mathrm{c} . /$ radicular $(\mathrm{cm})$ & $\mathrm{c} . /$ parte aérea $(\mathrm{cm})$ & c./radicular $(\mathrm{cm})$ & c./parte aérea $(\mathrm{cm})$ \\
\hline \multirow{2}{*}{ controle } & $4,48 \mathrm{a}^{*}$ & $1,35 \mathrm{ab}$ & $3,34 \mathrm{a}$ & $2,23 \mathrm{a}$ \\
$1 \%$ & $2,92 \mathrm{~b}$ & $1,51 \mathrm{a}$ & $1,57 \mathrm{~b}$ & $1,59 \mathrm{~b}$ \\
$2 \%$ & $1,80 \mathrm{c}$ & $0,95 \mathrm{~b}$ & $1,40 \mathrm{~b}$ & $1,39 \mathrm{bc}$ \\
$4 \%$ & $0,13 \mathrm{~d}$ & $0,17 \mathrm{c}$ & $0,77 \mathrm{c}$ & $1,23 \mathrm{c}$ \\
$8 \%$ & $0,02 \mathrm{~d}$ & $0,00 \mathrm{c}$ & $0,00 \mathrm{~d}$ & $0,00 \mathrm{~d}$ \\
\hline
\end{tabular}

* Médias seguidas pelas mesmas letras na coluna não diferem entre si pelo teste de Tukey, a 1\% de probabilidade. 
Tabela 3 - Valores médios da biomassa fresca (BF) e biomassa seca (BS) de plântulas de alface e picão-preto, submetidas aos extratos aquosos de frutos de umbu. URI, Frederico Westphalen, RS, 2008.

\begin{tabular}{ccccc}
\hline \multirow{2}{*}{ Tratamento } & \multicolumn{2}{c}{ alface } & \multicolumn{2}{c}{ picão-preto } \\
\cline { 2 - 5 } & $\mathrm{BF}(\mathrm{g})$ & $\mathrm{BS}(\mathrm{g})$ & $\mathrm{BF}(\mathrm{g})$ & $\mathrm{BS}(\mathrm{g})$ \\
\hline controle & $0,157 \mathrm{ab}^{*}$ & $0,008 \mathrm{a}$ & $0,061 \mathrm{a}$ & $0,006 \mathrm{a}$ \\
$1 \%$ & $0,189 \mathrm{a}$ & $0,007 \mathrm{a}$ & $0,078 \mathrm{a}$ & $0,006 \mathrm{a}$ \\
$2 \%$ & $0,137 \mathrm{bc}$ & $0,006 \mathrm{a}$ & $0,064 \mathrm{a}$ & $0,005 \mathrm{ab}$ \\
$4 \%$ & $0,086 \mathrm{c}$ & $0,003 \mathrm{~b}$ & $0,056 \mathrm{a}$ & $0,003 \mathrm{~b}$ \\
$8 \%$ & $0,000 \mathrm{~d}$ & $0,000 \mathrm{~b}$ & $0,000 \mathrm{~b}$ & $0,000 \mathrm{c}$ \\
\hline
\end{tabular}

* Médias seguidas pelas mesmas letras na coluna não diferem entre si pelo teste de Tukey, a $1 \%$ de probabilidade.

Tabela 4 - Características físico-químicas de extratos aquosos de frutos de umbu. URI, Frederico Westphalen, RS, 2008.

\begin{tabular}{ccc}
\hline Concentração & $\mathrm{pH}$ & PO* $(\mathrm{MPa})$ \\
\hline controle & 7,00 & 0,0000 \\
$1 \%$ & 4,83 & $-0,0170$ \\
$2 \%$ & 4,82 & $-0,0317$ \\
$4 \%$ & 4,72 & $-0,0683$ \\
$8 \%$ & 4,68 & $-0,1390$ \\
\hline
\end{tabular}

*Potencial osmótico.

É importante analisar o pH e o potencial osmótico dos extratos, pois esses podem conter solutos como açúcares, aminoácidos e ácidos orgânicos que podem mascarar o efeito alelopático e serem osmoticamente ativos (Ferreira \& Aquila, 2000). Gatti et al. (2004) recomendam que valores de potencial osmótico não ultrapassem -0,2 MPa em testes alelopáticos.

As reações de detecção de aleloquímicos revelaram apenas a presença do composto flavonoide (Tabela 5). Contudo não se pode afirmar que a presença de flavonoides tenha ocasionado os resultados obtidos, visto que as reações foram apenas de detecção da presença ou ausência. No entanto, sugere-se que a presença de compostos (incluindo ou não flavonoides) tenha ocasionado tais efeitos.

Os flavonoides representam uma importante classe de polifenóis e sua presença em vegetais parece estar relacionada com funções de defesa, controle de hormônios vegetais, inibição de enzimas e agentes alelopáticos (Alves $\&$ Santos, 2002). A presença de flavonoides com atividades fitotóxicas não é restrita em determinado órgão da planta, podendo aparecer também em outros órgãos (Chaves et al., 2001).

Tabela 5 - Análise fitoquímica de frutos de umbu, com vista à presença ou ausência de determinados compostos (aleloquímicos) de metabolismo secundário. URI, Frederico Westphalen, RS, 2008.

\begin{tabular}{cc}
\hline Aleloquímico & Frutos \\
\hline taninos & $-*$ \\
saponinas & - \\
flavonoides & $+* *$ \\
alcaloides & - \\
\hline
\end{tabular}

*Ausência. **Presença.

\section{CONCLUSÕES}

Nas condições em que foi realizado o experimento, pode-se concluir que os frutos de umbu interferiram na germinação e no crescimento inicial da alface e do picãopreto, em decorrência de efeitos alelopáticos.

$\mathrm{O} \mathrm{pH}$ e o potencial osmótico mantiveram-se dentro de padrões aceitáveis para a germinação e o crescimento inicial da alface e do picão-preto, sugerindo que a presença de compostos nos extratos tenha ocasionado os efeitos observados.

A germinação e o crescimento inicial do picão-preto mostraram-se mais sensíveis à ação dos extratos aquosos do umbu em relação à alface.

\section{REFERÊNCIAS BIBLIOGRÁFICAS}

ALVES, S.M.; SANTOS, L.S. Natureza química dos agentes alelopáticos. In: SOUZA FILHO, A.P.S.; ALVES, S.M. (Eds.). Alelopatia: princípios básicos e aspectos gerais. Belém: Embrapa Amazônia Oriental, 2002. p.25-47.

ANDRADE, H.M. de; BITTENCOURT, A.H.C.; VESTENA, S. Potencial alelopático de Cyperus rotundus L. sobre espécies cultivadas. Ciência e Agrotecnologia, Lavras, v.33, Edição Especial, p.1984-1990, 2009.

CHAVES, N.; SOSA, T.; ESCUDERO, J.C. Plant growth inhibiting flavonoids in exudates of Cistus ladanifer and in associated soils. Journal of Chemical Ecology, Orlando, v.27, n.3, p.623-631, 2001.

CHON, S.U.; KIM, Y.M. Herbicidal potential and quantification of suspected allelochemicals from four grass crop extracts. Journal Agronomy \& Crop Science, Berlin, v.190, p.145-150, 2004. 
CHOU, C.H. Roles of allelopathy in plant biodiversity and sustainable agriculture. Critical Reviews in Plant Sciences, Philadelphia, v.18, n.5, p.609-630, 1999.

CHUNG, I.M.; AHN, J.K.; YUN, S.J. Assessment of allelopathic potential of barnyard grass (Echinochloa crus-gall) on rice (Oriza sativa L.) cultivars. Crop Protection, Guildford, v.20, p.921-928, 2001.

COSTA, A.F. Farmacognosia. Lisboa: Fundação Calouste Gulbenkian, 2001. 992p.

EBERLEIN, C.V. Germination of Sorghum almum seeds and longevity in soil. Weed Science, Lawrence, v.35, n.6, p.796-801, 1987.

FALKENBERG, M.B.; SANTOS, R.I. dos; SIMÕES, C.M.O. Introdução à análise fitoquímica. In: SIMÕES, C.M.O.; SCHENKEL, E.P.; GOSMANN, G.; MELLO, J.C.P.; MENTZ, L.A.; PETROVICK, P.R. Farmacognosia: da planta ao medicamento. Porto Alegre: UFRGS; Florianópolis: UFSC, 2002. p.165182.

FERREIRA, A.G.; AQUILA, M.E.A. Alelopatia: uma área emergente da ecofisiologia. Revista Brasileira de Fisiologia Vegetal, Campinas, v.12, p.175-204, 2000 .

FERREIRA, A.G.; AQUILA, M.E.A.; JACOBI, U.S.; RIZVI, V. Allelopathy in Brazil. In: RIZVI, S.J.H.; RIZVI, V. (Eds.). Allelopathy: basic and applied aspects. London: Chapman \& Hall, 1992. p.243-250.

FRANÇA, A.C.; SOUZA, I.F. de; SANTOS, C.C. dos; OLIVEIRA, E.Q. de; MARTINOTTO, C. Atividades alelopáticas de nim sobre o crescimento de sorgo, alface e picão-preto. Ciência e Agrotecnologia, Lavras, v.32, n.5, p.1374-1379, set./out, 2008.

GATTI, A.B.; PEREZ, S.C.J.G. de A.; LIMA, M.I.S. Efeito alelopático de Aristolochia esperanzae O. Kuntze na germinação e no crescimento de Lactuca sativa L. e Raphanus sativus L. Acta Botânica Brasílica, São Paulo, v.18, n.3, p.459-472, 2004.

HOFFMANN, C.E.F.; NEVES, L.A.S. das; BASTOS, C.F.; WALLAU, G.L. da. Atividade alelopática de
Nerium Oleander L. e Dieffenbachia picta schott em sementes de Lactuca Sativa L. e Bidens pilosa L.

Revista de Ciências Agroveterinárias, Lages, v.6, n.1, p.11-21, 2007.

LORENZI, H. Árvores brasileiras: manual de identificação e cultivo de plantas arbóreas nativas do Brasil. Nova Odessa: Instituto Plantarum, 2000. $352 \mathrm{p}$.

MACÍAS, F.A.; MOLINILLO, J.M.G.; VARELA, R.M.; GALINDO, J.C.G. Allelopathy: a natural alternative for weed Control. Pest Management Science, London, v.63, n.4, p.327-348, 2007.

MACÍAS, F.A.; VARELA, R.M.; TORRES, A.; OLIVA, R.M.; MOLINILLO, J.M.G. Bioactive norsesquiterpenes from Helianthus annuus with potential allelopathic activity. Phytochemistry, Oxford, v.48, n.4, p.631-636, 1998.

MARASCHIN-SILVA, F.; AQUILA, M.E.A. Contribuição ao estudo do potencial alelopático de espécies nativas. Revista Árvore, Viçosa, v.30, n.4, p.547-555, jul./ago. 2006.

MAYEUX, H.S.; SCIFRES, C.J. Germination of goldenweed seed. Journal of Range Management, Davis, v.31, n.5, p.371-374, 1978.

MEDEIROS, A.R.M. de; LUCCHESI, A.A. Efeitos alelopáticos da ervilhaca (Vicia sativa $\mathrm{L}$.) sobre a alface em testes de laboratório. Pesquisa

Agropecuária Brasileira, Brasília, v.28, n.1, p.9-14, jan. 1993.

PERIOTTO, F.; PEREZ, S.C.J.G. de A.; LIMA, M.I.S. Efeito alelopático de Andira humilis Mart. Ex Benth na germinação e no crescimento de Lactuca sativa L. e Raphanus sativus L. Acta Botânica Brasílica, São Paulo, v.18, n.3, p.425-430, 2004.

RICE, E.L. Allelopathy. Orlando: Academic, 1984. 422p.

RODRIGUES, B.N.; PASSINI, T.; FERREIRA, A.G. Research on allelopathy in Brazil. In: NARWAL, S.S. Allelopathy update. Washington: Science, 1999. p.307323. 
SALISBURY, F.B.; ROSS, C. Plant physiology. Belmont: Wadsworth, 1992. 682p.

SMITH, A.E.; MARTIN, D.L. Allelopathic characteristics of three cool-season grass in the forage ecosystems. Agronomy Journal, Madison, v.8, n.2, p.243-246, 1994.

TEIXEIRA, C.M.; ARAÚJO, J.B.S.; CARVALHO, G.J. de. Potencial alelopático de plantas de cobertura no controle de picão-preto (Bidens pilosa $\mathrm{L}$.). Ciência e Agrotecnologia, Lavras, v.28, n.3, p.691-695, maio/jun. 2004.

VIEIRA, R.D.; CARVALHO, N.M. Testes de vigor em sementes. Jaboticabal: Funep, 1994. 164p.

ZHANG, Q. Potential role of allelopathy in the soil and the decomposition root of chinese-fir replant woodland. Plant and Soil, Dordrecht, v.151, n.2, p.205-209, 1993. 